\title{
LEI DE LAVAGEM DE DINHEIRO E REGRAS DO COAF - PONTOS DE CUIDADO E IMPORTÂNCIA DO COMPLIANCE
}

\author{
MONEY LAUNDERING LAW AND COAF RULES - POINTS OF CARE AND IMPORTANCE OF \\ COMPLIANCE
}

\author{
Letícia Sangaleto Terron \\ Mestre \\ Universidade de Marília (UNIMAR-SP) \\ Marilia/SP. Brasil \\ leticiasanga@bol.com.br \\ Elias Marques Medeiros Neto \\ Pós Doutor \\ Universidade de Marília (UNIMAR-SP) \\ Marilia/SP. Brasil \\ eliasmarquesneo@hotmail.com
}

Resumo: A Lei de Lavagem de Dinheiro e tipifica condutas que acarretem ao indivíduo dinheiro adquirido de forma criminosa sendo apresentada para dentro da economia de uma maneira que se assemelhe correta e legal. No Brasil tem-se o Conselho de Controle de Atividades Financeiras (COAF) que é o órgão competente e principal nas ações de inteligência para precaução e inibição a esse crime. O objetivo do presente estudo é apresentar a importância desse Conselho juntamente com a utilização do programa de compliance. A metodologia utilizada para a elaboração deste foi hipotético-dedutivo com pesquisas doutrinárias, em mídias digitais e documentais. Conclui-se, que com a globalização, a tendência dos negócios seja em torno das empresas que são e estão em consonância ao programa de compliance evitando o crime de lavagem de dinheiro e agindo em consonância com as regras legais.

Palavras-chave: Lavagem de Dinheiro. Compliance. Globalização.

\begin{abstract}
The Money Laundering Law and typifies conducts that bring criminally acquired money to the individual, being presented into the economy in a way that resembles correct and legal. In Brazil, there is the Financial Activities Control Council (COAF), which is the competent and main body in intelligence actions to prevent and prevent this crime. The purpose of this study is to present the importance of this Council together with the use of the compliance program.The methodology used for the elaboration of this was hypothetical-deductive with doctrinal researches, in digital and documentary media It is concluded that, with globalization, the business trend is around the companies that are and are in line with the compliance program avoiding the money laundering and acting in accordance with legal rules.
\end{abstract}

Keywords: Money laundry. Compliance. Globalization.

Para citar este artigo (ABNT NBR 6023:2018)

TERRON, Leticia Sangaleto; MEDEIROS NETO, Elias Marques. Lei de lavagem de dinheiro e regras do COAF - pontos de cuidado e importância do Compliance. Revista Thesis Juris - RTJ, São Paulo, v. 9, n. 2, p. 238-257, jul./dez. 2020. http://doi.org/10.5585/rtj.v9i2.10346. 
TERRON, Leticia Sangaleto; MEDEIROS NETO, Elias Marques. Lei de lavagem de dinheiro e regras do COAF - pontos de cuidado e importância do Compliance

\section{Introdução}

O presente trabalho tem como escopo analisar o compliance em suas peculiaridades e trazer a sua importância no combate e prevenção ao crime de lavagem de dinheiro. Apresentar o que é o COAF, o Conselho de Controle de Atividade Financeiras, que foi instituído para ser a Unidade de Inteligência Financeira do Brasil, e trazer sua importância na responsabilidade de abranger as combinações financeiras onde as pessoas físicas ou jurídicas (empresas) brasileiras estão ou não produzindo movimentações impróprias e demudando o dinheiro que foi adquirido de forma ilegal em, visivelmente, legal.

O objetivo principal do estudo é demonstrar o valor do compliance no processo de prevenção e combate à lavagem de dinheiro no Brasil, pois essa atividade criminosa, movimenta uma soma expressiva de dinheiro e as empresas que se utilizarem desse programa estarão em consonância com o mercado globalizado.

Será visto no decorrer do artigo, mais precisamente nos itens 3 e 4, que o crime de lavagem de dinheiro é dividido em três fases diferentes - colocação, ocultação e integração, e que tem como finalidade ladear a descoberta desse crime afetando os lucros ilegais, atrapalhando o rastreamento do dinheiro intrincado nas ligações ilegítimas.

Em auxílio à prevenção e combate ao crime anteriormente mencionado, será estudado no item 5 a aplicabilidade do programa de compliance que pode ser visto como um conjugado de normas para disciplinar e alinhar a conduta da empresa fazendo com que a mesma siga as normas legais e políticas governamentais alusivas ao setor da coorporação, com a intenção cardeal de prevenir e coibir atos ilícitos. Dessa feita, é assim possível o programa de compliance diminuir ou até mesmo conter o crime de lavagem de dinheiro dentro da empresa que contenha esse programa?

Tratará, também, o presente estudo, sobre o fato da empresa que tiver o programa de compliance ter uma gama de atratividade ao negócio, já que com a globalização a coletividade vem, considerando o consumo ético e a companhia ética e sustentável, estabelecendo-se das empresas conscientização em relação aos costumes e condutas que se reproduzem nesses valores. Para que isso aconteça, compete à empresa treinar seus funcionários para o programa de compliance.

A metodologia utilizada para o alcance do feitio deste artigo foi o método hipotéticodedutivo, pelo meio da apreciação de doutrinas, periódicos científicos, internet, casos práticos, leis e documentos ligados diretamente ao assunto apresentado. 
TERRON, Leticia Sangaleto; MEDEIROS NETO, Elias Marques. Lei de lavagem de dinheiro e regras do COAF - pontos de cuidado e importância do Compliance

\section{Aspectos relevantes sobre o COAF}

Ligado ao Governo Federal, o Conselho de Controle de Atividades Financeiras (COAF), é competente nas ações de inteligência para precaução e inibição a lavagem de dinheiro, ocultação de patrimônio e o financiamento aos atos de terrorismo. É um órgão vinculado ao Ministério da Economia e analisa as combinações financeiras suspeitas que têm nexo com a população do Brasil. Ao COAF cabe: disciplinar e aplicar penas administrativas; receber, examinar e identificar fatos suspeitos de transações ilícitas; informar às autoridades; e, coordenar e propor mecanismos de cooperação e de troca de informações. (VIEIRA, 2018).

Esse Conselho foi criado a partir da Lei 9.613/98 - conhecida Lei da Lavagem de Dinheiro - é um dos principais órgãos responsáveis por originar visibilidade pública ao assunto da lavagem de dinheiro, e de acordo com o artigo 14, da referida Lei:

Fica criado, no âmbito do Ministério da Justiça e Segurança Pública, o Conselho de Controle de Atividades Financeiras - COAF, com a finalidade de disciplinar, aplicar penas administrativas, receber, examinar e identificar as ocorrências suspeitas de atividades ilícitas previstas nesta Lei, sem prejuízo da competência de outros órgãos e entidades.

Dessa maneira, é oportuno aos bancos, joalherias, corretoras e outras, informar ao COAF toda e qualquer transação financeira acima ou no valor de R \$10.000,00 e também, os casos que dentro do mesmo mês, houver suspeita de transação por uma mesma pessoa. Essas transações podem ser em moeda nacional ou estrangeira, ouro ou qualquer metal ou pedra preciosa, títulos, ações, valores mobiliários, ou seja, tudo que puder ser convertido em dinheiro no valor já mencionado.

Não somente as transações suspeitas têm que ser informadas, incumbindo também aos Bancos ou Instituições Financeiras informar ao COAF, retirada ou depósito em espécie, ou pedido para saque, no valor igual ou superior a R\$100.000,00. (FREITAS JÚNIOR, 2017, p. $135)$.

É necessário que as Instituições Financeiras registrem e guardem todas as transações acima de R $\$ 10.000,00$, mas reportar ao COAF apenas as que considerarem suspeitas.

Assim, o Conselho de Controle de Atividade Financeiras, foi criado para ser a Unidade de Inteligência Financeira do Brasil, tendo como fundamental responsabilidade entender das transações financeiras onde as pessoas físicas ou jurídicas (empresas) brasileiras estão ou não obtendo movimentações impróprias e transformando o dinheiro que foi obtido de forma ilegal em, visivelmente, legal. Os relatórios lançados pelo COAF são sigilosos e destinam-se, 
exclusivamente, às autoridades que competem investigar. Dessa mesma maneira, o COAF tenta evitar que essas transações possam vir a financiar, inclusive, o terrorismo.

\begin{abstract}
Outro órgão criado nos anos 1990 que impactou fortemente o sistema anticorrupção é o Conselho de Controle de Atividades Financeiras (Coaf), vinculado ao Ministério da Fazenda. Instituído pela legislação antilavagem de dinheiro (Lei 9.613/1998) e diretamente ligado à estrutura concebida internacionalmente para lidar com o movimento de ativos de origem ilícita, o Coaf centraliza informações financeiras referentes aos setores econômicos legalmente obrigados a comunicar transações que alcancem determinados valores ou sigam certos padrões. Como "unidade de inteligência financeira", cabe ao Coaf também, entre várias outras tarefas, cruzar informações financeiras coletadas com outras produzidas por agências estatais (como a Receita Federal e a Polícia Federal), além de realizar intercâmbio dessas informações com outros países. (MACHADO; PASCHOAL, 2016).
\end{abstract}

Esse órgão atua junto às estruturas internacionais, tornando-se o coordenador nacional contíguo a foros internacionais que também trabalham na precaução e na atuação contra a lavagem de dinheiro e ao financiamento do terrorismo.

A pessoa, física ou jurídica, obrigada por passar as informações ao COAF tem que fazêlo no prazo de $24 \mathrm{~h}$, conforme o artigo 11, II, da Lei de Lavagem de Dinheiro. A partir do recebimento da informação o COAF faz inúmeros cruzamentos de informações em todas suas bases de dados produzindo o Relatório de Inteligência Financeira (RIF), sigiloso como já dito, e remete às autoridades responsáveis para uma análise mais minuciosa. Ao COAF cabe apenas indicar indícios de crimes nessas transações financeiras e quem findará atestando ser crime ou não, será a autoridade competente através de uma investigação. Esse órgão é composto por um presidente, com indicação feita pelo Ministro da Economia, alteração feita pela Medida Provisória (MP) 870/2019 e nomeado diretamente pelo Presidente da República, e mais onze componentes, sendo eles servidores públicos de diferentes órgãos públicos, exemplo: Banco Central, Comissão de Valores Mobiliários, Ministério da Justiça e Segurança Pública etc. (Medida Provisória 870/19).

O Relatório de Inteligência Financeira é a consequência das apreciações de inteligência financeira que decorrem das comunicações auferidas, de intercâmbio de denúncias e informações.

Há dois tipos de relatório: o espontâneo, também conhecido como de ofício, que é preparado por ação do COAF a partir da apreciação de comunicações ou denúncias; e, o de intercâmbio, que é disposto para atendimento a requerimento de intercâmbio de informações por autoridades nacionais ou por Unidades de Inteligência Financeira.

Para que todas essas informações fiquem armazenadas, o COAF possui um sistema que comporta que todos os responsáveis enviem as informações das operações financeiras ocorridas, possam efetuar consultas à lista disponível, e também, façam cadastros de pessoas 
obrigadas a estarem incluídas nesse órgão. Esse sistema é conhecido como SISCOAF - Sistema de Controle de Atividades Financeiras.

Conforme divulgado no site do Ministério da Justiça e Segurança Pública:

\begin{abstract}
De 1998, até novembro de 2018, o COAF já produziu cerca de 40 mil Relatórios de Inteligência Financeira (RIFs), que citam aproximadamente 1,1 milhão de pessoas. Isso não quer dizer que são 1,1 milhão de criminosos. Essa é uma forma de "seguir o dinheiro" e dar subsídios para que a Polícia Federal e o Ministério Público possam rastrear esse caminho e fazer diligências investigativas. Somente em 2017, a atuação do COAF, juntamente com o Ministério Público e autoridades policiais, possibilitou o bloqueio judicial de $\mathrm{R} \$ 46$ milhões no Brasil e no exterior, relacionados a investigações sobre lavagem de dinheiro e outros crimes. Na vertente de supervisão, desde o início de suas atividades, a atuação do COAF resultou na aplicação de $\mathrm{R} \$ 9,3$ milhões em multas pecuniárias a pessoas obrigadas que deixaram de cumprir com suas obrigações legais.
\end{abstract}

Verifica-se com esses dados que a contribuição da COAF é extremamente necessária e se faz indispensável para que o país consiga eliminar do seu rol de crimes mais praticados, a lavagem de dinheiro.

\title{
3 A lei de lavagem de dinheiro e suas evidências
}

O termo "lavagem de dinheiro" também é conhecido como branqueamento de capitais, pois advém da ocorrência de que o dinheiro obtido de maneira desonesta é "sujo" e, assim, carece de ser lavado para se transformar em "limpo". Essa nomenclatura foi apontada pela primeira vez pelo jornal inglês The Guardian popularizando-se nos anos de 1970, com o Caso Watergate, quando um informante aconselhou um repórter desse mesmo jornal a "seguir o dinheiro", e este descobriu uma ilegalidade no Comitê de Campanha do então presidente americano Nixon, onde direcionavam dinheiro de fundos ilegais de campanha para o México e depois regressava para os Estados Unidos, pelo meio de uma corporação em Miami. (ARO, 2013).

Diversamente do mencionado acima, o termo "lavagem de dinheiro" teria origem bem anterior ao ano de 1970. Em 1928 esse termo já teria sido utilizado com os crimes praticados por Al Capone, que teria adquirido uma série de lavanderias na cidade de Chicago, constituindo um empreendimento de fachada para lavar o dinheiro advindo da comercialização ilegal de bebidas, em decorrência da Lei Seca, da prostituição, dos jogos e da extorsão. (BARROS, 2013). 
[...] filho de imigrantes italianos provindos da região de Nápoles, nascido em Nova York. Esse conhecido infrator da lei assumiu, por volta de 1920, o controle do crime organizado na cidade de Chicago, tornando-se milionário com a venda de bebidas ilegais. Foi preso por sonegação fiscal após sofrer rigorosa investigação em suas declarações de renda. (BARROS, 2013, p. 33).

É muito utilizado, também, o termo "lavagem de dinheiro inverso", que configura, como o próprio nome diz, o inverso do conceito de lavagem de dinheiro. Aqui, o dinheiro inicial é limpo, ou seja, é lícito e legal, a finalidade dele é que é ilícita. É um dinheiro obtido na legalidade, mas que será usado, por exemplo, para o terrorismo.

Foi a Itália a pioneira em legalizar o crime de lavagem de dinheiro, no ano de 1978. Havia nessa época um grupo conhecido como Brigadas Vermelhas, grupo armado que perpetrava inúmeras ações para desconjuntar o domínio político do Estado. Nesse mesmo ano, diversos sequestros foram feitos, tendo como intenção final o proveito financeiro, onde as Brigadas Vermelhas sequestraram o democrata cristão Aldo Moro - considerado o verdadeiro presidente italiano - apresentando repercussão universal. Dois meses após seu sequestro Moro fora assassinado, e devido ao alvoroço social o governo italiano converteu um antigo Decreto-lei em Lei 191 de 18 de maio de 1978, tornando crime a substituição de dinheiro ou de valores provenientes de roubo, extorsão qualificada ou extorsão mediante sequestro por outros valores ou dinheiro (ARO, 2013).

Os anos 80 foram o marco nas convenções internacionais para criação de meios para combater o crime de Lavagem de Dinheiro: a Convenção de Viena em 1988; Convenção de Palermo em 2000; e, Mérida em 2003.

A Convenção de Viena foi instituída para repreender o comércio ilícito de drogas e fixou um significado sobre o crime de lavagem de dinheiro que é acolhida universalmente. Ficou acordado entre os países que participavam do Tratado que os mesmos estariam obrigados a cunhar uma tipificação penal tendo como fim culpar o mau ator que escondesse bens ou dinheiro advindos do tráfico internacional de drogas. Proporcionou inovações na colaboração internacional, tendo como meta ser de encargo de todos os países, em atuação contígua, a única maneira para acabar com as atividades internacionais desse crime. Em 1991 o Brasil passou a ser signatário dessa Convenção, através do Decreto 154/91. No ano de 2000, foi criada a Convenção de Palermo, que trouxe respeitáveis considerações sobre o crime organizado, inclusive procurou expor diversos tipos penais que pudessem ser acolhidos como crimes que antecedessem o crime de lavagem de dinheiro, que pela Convenção de Viena era só o crime de tráfico de entorpecentes. Através do Decreto 5015, no ano de 2004, o Brasil coligou a essas regras. (MENDRONI, 2015). 
Em 2006, o Brasil, através do Decreto 5.687, assinou a Convenção de Mérida ou Convenção das Nações Unidas Contra a Corrupção, que tinha como alvo combater a corrupção. Essa Convenção trouxe como inovação medidas que as instituições financeiras devem tomar quanto às transações de valores.

\begin{abstract}
A recuperação de ativos é uma importante inovação e um princípio fundamental da convenção. Os Estados Partes devem apoiar-se entre si com extensas medidas de cooperação e assistência neste campo, a fim de fazer valer os interesses das vítimas e dos donos legítimos desses recursos. Os Estados Partes devem solicitar suas instituições financeiras a: verificar a identidade de seus clientes; determinar a identidade de beneficiários de contas volumosas; aplicar controle reforçado a contas mantidas por altos funcionários públicos; reportar transações suspeitas às autoridades competentes; e prevenir o estabelecimento de bancos sem presença física. (UNODC, 2019).
\end{abstract}

O conceito lavagem de dinheiro versa na obtenção de dinheiro de forma irregular, ilegal, ilícita e trazer para dentro da economia de uma maneira que pareça correta e legal, como já mencionado. O crime de lavagem de dinheiro vem regulado pela Lei 9.613/98, onde traz a ocultação ou dissimulação de bens, direitos e valores, nas infrações penais a serem penalizadas pela mesma. Conforme Marco Antonio de Barros (1998, p. 15):

\footnotetext{
Crime de lavagem consiste na operação financeira ou transação comercial que oculta ou dissimula a incorporação, transitória ou permanente, na economia ou no sistema financeiro do País, de bens, direitos ou valores que, direta ou indiretamente, são resultado ou produto dos seguintes crimes: a) tráfico ilícito de substâncias entorpecentes ou drogas afins; b) terrorismo; c) contrabando ou tráfico de armas, munições ou material destinado à sua produção; d) extorsão mediante seqüestro; e) praticados contra a Administração Pública; f) cometidos contra o sistema financeiro nacional; h) praticados por organização criminosa.
}

A Lei é clara em seu artigo 1ํㅡㄴ no sentido de que para se alcançar a tipificação do delito de lavagem de dinheiro é necessário se ter anteriormente a ele, a prática de uma infração antecedente. É notório, assim, que o crime de lavagem de dinheiro tem caráter acessório derivado ou dependente - mediante analogia de dependência instrumental e peculiar com ilícito penal cometido anteriormente. Dessa maneira, descreve-se que a lavagem de dinheiro é, um "crime remetido", pois para existir depende necessariamente de ocorrência criminosa prévia. (MACHADO, 2012).

Essa referida Lei trazia como crime precedente um rol taxativo de possibilidade de crimes em seu $\operatorname{artigo} 1^{\circ}$ : 




Em 2012, houve uma alteração no artigo $1^{\circ}$, perpetrando que qualquer contravenção ou crime, enquadre-se como crime anterior para configurar o crime de lavagem de dinheiro, desde que seja apropriado de acometer ativos de procedência não lícita. Conforme a Lei 12.683/12, “§ 1o A denúncia será instruída com indícios suficientes da existência da infração penal antecedente, sendo puníveis os fatos previstos nesta Lei, ainda que desconhecido ou isento de pena o autor, ou extinta a punibilidade da infração penal antecedente." $\mathrm{O}$ artigo $2^{\circ}$, da aludida Lei, revogou os incisos do artigo $1^{\circ}$, da Lei 9.613/98, sendo adotada a Teoria da Acessoriedade Limitada.

Esta é, sem dúvida, a inovação mais impactante da Lei 12.683/2012: a eliminação do rol de crimes antecedentes da Lei de Lavagem de Dinheiro. Ampliou-se significativamente o espectro do tipo penal de branqueamento de capitais. Situações antes atípicas deixam de sê-lo. Ainda será necessário observar o binômio infração antecedente / lavagem de ativos. Porém, não há mais uma lista fechada (numerus clausus) de delitos precedentes. Qualquer infração penal (e não mais apenas crimes) com potencial para gerar ativos de origem ilícita pode ser antecedente de lavagem de dinheiro. Dizendo de outro modo: a infração antecedente deve ser capaz de gerar ativos de origem ilícita. Infrações penais que não se encaixem neste critério (o de ser um "crime produtor") não são delitos antecedentes. (ARAS, 2002).

Observa-se que o Direito Penal no Brasil abraça o preceito de bipartição, onde a infração penal configura o gênero, que se divide em contravenção penal e crime. O autor Marcelo Medroni (2015, p.20), sobre a lavagem de dinheiro, dita: “poderia ser definida como o método pelo qual um indivíduo ou uma organização criminosa processa os ganhos financeiros obtidos com atividades ilegais, buscando trazer a sua aparência para obtidos licitamente". Além disso, acredita que o aparelhamento delituoso não permanece sem a lavagem de dinheiro, pois para prosseguir com o delito iterado, demanda de uma simulação para que tudo pareça ter sido feita de maneira correta. 
A lavagem de dinheiro é dividida em três etapas diferentes. Essas etapas têm o desígnio de evadir o descobrimento desse crime dissimulando as benesses ilegais, atrapalhando o rastreamento do dinheiro envolvido nas transações ilegais. São três as etapas: colocação, ocultação e integração.

A primeira etapa é a conhecida como "colocação", que incide em se encontrar uma maneira por onde o dinheiro ilícito deva ser alocado, e o meio mais utilizado na atualidade são os paraísos fiscais que são localidades que movimentam o dinheiro sem uma abrupta investigação de sua origem ou do favorecido final.

Outra fase é a denominada de "ocultação" e também conhecida como a fase da concretização da lavagem de dinheiro. Cabe a essa fase aniquilar as pistas deixadas pelo caminho. Os indícios de evidência necessitam ser apagados, antes da investigação do ato criminoso. A forma mais encontrada na fase da "ocultação" é a movimentação do dinheiro eletronicamente para diversas contas bancárias em países que preservam as leis de sigilo bancário, deixando essas contas anônimas.

A terceira e última fase é a da "integração", onde os envolvidos trocam contratos que promovam o alargamento de suas atividades ilícitas. Essa fase é a responsável por integrar os benefícios financeiros acarretados pela lavagem de dinheiro como se fossem lícitos, através da inclusão na economia formal, como por exemplo, a aquisição de bens com registros apropriados para explicar o capital de maneira legalizada. Há o convertimento do ilícito em ativo lícito, dificultando descobrir a origem do dinheiro com as contínuas e implexas fases etapas de mascaramento.

Dessa maneira, para dissimular os lucros obtidos ilicitamente sem envolver os criminosos, a lavagem de dinheiro se dá através de um artifício eficaz onde há distância dos proventos de sua origem para que se impeça uma ligação com o crime. Após, é necessário que haja um mascaramento nas diversas movimentações financeiras na tentativa de dificultar a busca desses recursos. E por fim, a disponibilização do dinheiro, mais uma vez pelos os maus atores para ser avaliado como limpo.

\section{A lavagem de dinheiro e os métodos de prevenção e combate do COAF}

O combate ao crime de lavagem de dinheiro é a modo mais hábil para batalhar as organizações criminosas, pois para sua mantença é imperativo um giro grande de capital e esse capital muitas vezes sobrevém da lavagem de dinheiro, do tráfico de drogas e outros mais crimes. A maioria dos grupos criminosos age de forma globalizada estabelecendo uma 
TERRON, Leticia Sangaleto; MEDEIROS NETO, Elias Marques. Lei de lavagem de dinheiro e regras do COAF - pontos de cuidado e importância do Compliance

colaboração internacional para o combate dos mesmos. O Brasil, atualmente, conta com o FATF, Financial Action Task Force, e também, é membro do GAFI, Grupo de Ação Financeira Internacional, que tem como finalidade estabelecer indicações sobre a prevenção e repressão ao crime de lavagem de dinheiro, além de financiamento ao terrorismo advindo da apreensão dos frutos dos crimes perpetrados. (LIMA; GULARTE, 2017)

Com a Lei 9.613/98, criou-se no Brasil o COAF, Conselho de Controle de Atividades Financeiras. Esse Conselho abarcou a regulação, fiscalização e a aplicação de penas administrativas atinentes à prevenção à lavagem de dinheiro e ao financiamento do terrorismo, englobando tanto pessoas físicas quanto jurídicas e de diferentes ramos da economia, como delineado no item anterior.

A essas pessoas determinadas pela Lei cabe uma maior responsabilidade ao identificar o cliente e manter uma relação dos mesmos e conservação de todas as operações e comunicações suspeitas, ficando ainda, sujeitas às penalizações administrativas por não exercerem as obrigações cabíveis.

É admissível ao COAF exercer a função de Unidade de Inteligência Financeira no Brasil, onde há trocas de informações com 180 países (que também têm UIFs) colaboradores na precaução e luta contra o crime de lavagem de dinheiro e de financiamento ao terrorismo. O principal objetivo é "seguir o dinheiro", e a troca de elementos informativos, no mundo globalizado, feita por meio da tecnologia de ponta é fundamental para a inibição desses crimes citados. (BOTELHO, 2018)

O dinheiro a ser perseguido é aquele advindo de crimes e movimentado por grupos criminosos e muitas vezes terroristas, inclusive movido por organizações corruptas, na tentativa de que esse dinheiro seja confiscado e devolvido a suas vítimas, inclusive aos cofres públicos.

Além do intercâmbio de informações com diversos países, a COAF, também atua incansavelmente na esfera nacional, cooperando e veiculando dados de inteligência financeira junto à ENCCLA (Estratégia Nacional de Combate à Corrupção e à Lavagem de Dinheiro), onde participam mais de 70 órgãos e autarquias, todos com a mesma finalidade que é de dar fim ao crime de lavagem de dinheiro. (SAAD; MACHADO, 2017)

Conforme o próprio site da ABIN (Agência Brasileira de Inteligência) essa agência também faz parte das iniciativas governamentais brasileiras na busca de findar o crime de lavagem de dinheiro, proporcionando análises de inteligência e estimativas que auxiliam na prudência e coação a esse tipo de crime, inclusive, levando para dentro dos Ministérios e da Presidência da República suas informações. 


\begin{abstract}
A ABIN integra a Estratégia Nacional de Combate à Corrupção e à Lavagem de Dinheiro (ENCCLA) e tem assento no Conselho de Controle de Atividades Financeiras (COAF), unidade de Inteligência financeira do Brasil.

A ABIN integra subgrupos de trabalho específicos da ENCCLA e é responsável pelo desenvolvimento de análise de risco que avalia as vulnerabilidades da estrutura financeira nacional ao crime de lavagem de dinheiro. $\mathrm{O}$ órgão tem trabalhado em conjunto com as demais instituições para adaptar a metodologia de avaliação de risco desenvolvida pela ABIN para os grandes eventos esportivos - denominada Arena para atender às necessidades específicas de avaliação de riscos da lavagem de dinheiro no país. (ABIN).
\end{abstract}

Assim como com a ABIN, o Conselho de Controle de Atividades Financeiras - COAF - opera conjuntamente com várias outras estruturas, como Polícia Federal, Receita Federal, Banco Central e Ministério Público, e conta com menos de 50 funcionários. Pelo simples fato desse órgão permitir ingresso a um vasto número de transações financeiras duvidosas sem necessidade de uma averiguação precedente e, principalmente, sem uma autorização de juiz, fica cabível uma forma mais agilizada aos responsáveis pela investigação de obter informações imprescindíveis ao combate ao crime de lavagem de dinheiro. Há uma desburocratização na aquisição de informações suspeitas, possibilitando a busca e apreensão de bens e dinheiro ilícitos.

O COAF não é um órgão de investigação e sim de controle, como o próprio nome profere, pois na prática ele funciona como uma enorme base de informações onde reúne as transações financeiras, que conforme a Lei 9.613/98 necessitam de ser comunicadas pelos bancos, joalherias, seguradoras e demais. É o principal responsável por perceber se pessoas e empresas brasileiras estão ou não realizando movimentações indevidas e cometendo o crime de lavagem de dinheiro.

As RIFs, como já mencionadas anteriormente, podem ser perpetradas, na prática, de duas formas: de ofício, que são aquelas feitas por iniciativa da própria COAF, através do SISCOAF; ou, por intercâmbio, que são aqueles relatórios que atendem solicitações de autoridades competentes. Esses relatórios têm aumentado significativamente com o passar dos anos e estado presentes nas principais operações contra o crime da lavagem de dinheiro no Brasil.

Conforme Figueiredo e Chagas (site Politize, 2019) o COAF na prática funciona da seguinte maneira: 
1) As várias pessoas (físicas e jurídicas) descritas no capítulo $\mathrm{V}$ da Lei $\mathrm{n}^{\circ}$ $\underline{9613 / 98}$ enviam comunicações sobre suas movimentações financeiras. As informações são armazenadas no SISCOAF e analisadas pelo sistema, em conjunto com outros dados disponíveis (CPF, CNPJ, Declaração de Operações Imobiliárias, etc).

2) Quando detectado um sinal de alerta em alguma dessas movimentações, o sistema calcula o risco de ser uma atividade ilícita.

3) Se o risco for elevado, são criadas pastas chamadas "Caso" para análises mais aprofundadas.

4) A análise dos "Casos" resulta em Relatórios de Inteligência Financeira (RIF).

5) Quando constatados indícios de práticas ilícitas, como lavagem de dinheiro, os RIFs são encaminhados às autoridades competentes (como a Polícia Federal, por exemplo) para os procedimentos cabíveis. Por si só, o COAF não pode investigar, julgar ou prender, apenas analisar. (grifo nosso).

O Conselho de Controle das Atividades Financeiras faz-se cada vez mais importante na luta contra o crime da lavagem de dinheiro e financiamento ao terrorismo, pois é imprescindível o seu levantamento de informações quando há indício de algo contrário à lei. O constante desenvolvimento da tecnologia e a oferenda de invenções e ofícios na área da finança relacionados à coletividade em conjunto com a criatividade e inteligência das mentes criminosas propiciam o aparecimento de novas tipologias - descrições peculiares de elementos, objetivando buscar amostras e relações no sistema - o tempo todo. Dessa maneira, o COAF deve estar preparado para reconhecer essas novas tipologias.

A I Coletânea de Casos Brasileiros de Lavagem de Dinheiro (2011) traz alguns casos que ocorrem corriqueiramente: Sistema financeiro paralelo; Uso do mercado de valores mobiliários para a ocultação de remetentes e destinatários de recursos em espécie; Fraude contra clube ou fundo de investimento por meio de opções flexíveis de compra (mercado de balcão) e transferência dos recursos para o exterior; Compra de imóveis com dinheiro em espécie originado do tráfico internacional de drogas por meio de fraude cambial; Lavagem de dinheiro por meio de cartório de protestos; Operações fraudulentas com fundos de investimento imobiliário e fundos de pensão; Internalização de recursos de origem ilícita por meio de nãoresidentes; e outros mais.

Assim, ao COAF é aceitável uma varredura incansável nas informações que lhes são transferidas, pois sem seus relatórios dificilmente se consegue uma prevenção ao crime de lavagem de dinheiro e financiamento ao terrorismo.

\section{Compliance e suas contribuições ao mundo corporativo e ao combate e prevenção do crime de lavagem de dinheiro}

Compliance vem do verbo inglês to comply e tem como significado agir de acordo ou estar em conformidade com algo. É uma instrução que tende à precaução e a minimização de 
TERRON, Leticia Sangaleto; MEDEIROS NETO, Elias Marques. Lei de lavagem de dinheiro e regras do COAF - pontos de cuidado e importância do Compliance

temeridades as quais as organizações estão sujeitas, podendo afetar o negócio acarretando muitos prejuízos para as empresas por descumprirem as regulações vigentes. (KEMPFER; BASTITI, 2017)

Conforme Bittencourt (2014) o termo compliance traduz, em sentido literal, a acepção de atuar de acordo com uma regra ou comando. Refere-se, então, dessa maneira, que o compliance procura desempenhar todas as normas que lhe sejam impostas, sendo elas de dentro da própria organização, ou normas externas.

Pode ser vista como um conjunto de normas para disciplinar e alinhar o comportamento coorporativo da pessoa jurídica seguindo as normas legais e políticas governamentais referentes ao setor da empresa, com a finalidade principal de prevenir e coibir atos ilícitos. Dessa maneira, para facilitar a compliance é necessário criar composições internas e métodos de integridade, auditoria e estímulos à comunicação de anormalidades (canais de denúncias), que providenciem uma análise e preparem um prognóstico dos comportamentos e de seus cooperadores, aplicando-se os códigos de ética já no âmbito interno da organização.

Há uma grande disposição de individualizar o compliance como uma presteza operacional ("estar em compliance") e não estratégica ("ser compliant"), adornada à analogia organizacional e a condutas éticas. Estar em compliance é exercer a legislação e as políticas internas por simples compulsão ou para amortizar fortuitas penalidades, caso a empresa padeça uma punição. Ser compliant é a execução conscienciosa e decidida da legislação e de políticas internas, conduzida pelos princípios e valores que arranjam a identidade da organização, propendendo sua longevidade.

O Conselho Administrativo de Defesa Econômica, CADE, (2016) assegura que através das ideias de compliance, os atuantes robustecem seu compromisso com o ali explicitado, ou seja, valores e objetivos, principalmente com a execução da legislação. Esse objetivo é muito audacioso, assim ele solicita além da elaboração de uma cadeia de métodos, uma modificação cultural corporativa.

Muito bem explicitado por Silveira e Saad-Diniz (2015, p. 255), o compliance pode ser vista:

Os pressupostos dados à noção de compliance podem, por vezes, parecer comezinhos. Mas não o são, ainda mais quando da verificação de sua integração com o Direito penal. Sua estrutura é bastante interessante, mas causa uma certa preocupação quando vista sob o prisma penal. É de se ver, de toda forma, que a técnica dos programas de compliance não se mostra apenas como ornamentação de estilo das teorias do consenso - e nem mesmo da arbitragem ou dos sistemas de auditoria interna. Ela vai além: mostra-se como uma aceitação institucionalizada, que comina as variadas possibilidades de comportamento decisório no âmbito empresarial. Orienta-se, em verdade, pela finalidade preventiva, por meio da programação de uma série de condutas que estimulam a diminuição dos riscos da atividade. 
TERRON, Leticia Sangaleto; MEDEIROS NETO, Elias Marques. Lei de lavagem de dinheiro e regras do COAF - pontos de cuidado e importância do Compliance

O compliance é aceito como uma tática de atratividade do negócio, já que com a globalização a sociedade vem, de forma crescente, levando em consideração o consumo ético e a empresa ética e sustentável, sendo exigido das empresas conscientização em relação aos costumes e condutas que se espelham nesses valores. Quanto maior a fidelidade, comprometimento e satisfação do sujeito dentro de uma organização ética e boas técnicas de direção corporativa o mesmo passa a produzir mais. Para isso, cabe à empresa preparar seus funcionários para o compliance com treinamentos.

Ter a disciplina de compliance na organização traz inúmeros melhoramentos. Alguns deles são: benefício competidor em relação à concorrência; fascinação de investidores e investimentos; assimilação de riscos e prevenção de dificuldades; ganho de credibilidade; minimização de riscos: progresso da eficácia e qualidade dos serviços/produtos; requisito legal; aumento da governança; fator atenuante de multas; concretização de uma cultura organizacional; sustentabilidade; alinho eficaz de não-conformidades; facilidade de aquisições.

Não existe a obrigatoriedade de se ter um sistema de compliance nas empresas brasileiras, mas em 2013 foi sancionada a Lei 12.846, Lei Anticorrupção, que trata sobre: “a responsabilização administrativa e civil de pessoas jurídicas pela prática de atos contra a administração pública, nacional e estrangeira", abordando assim, a corrupção das empresas que lesam a administração pública, tendo como exemplo as organizações que prometem vantagem indevida a um agente público para que o mesmo fraude uma licitação.

Esses atos, anteriormente a essa Lei praticados, já eram inaceitáveis. A diferença é que agora existe uma Lei Específica que asseverou as suas consequências, fazendo com que o compliance, mesmo não sendo obrigatório, como já dito, torne-se mais frequente nas empresas e essencial para segurança das mesmas. A má conduta de um único membro dessa organização faz com que a corporação inteira sofra as consequências trazidas pela Lei mencionada.

No Rio de Janeiro a Lei 7.753/17, e no Distrito Federal a Lei 6.112/18, estipularam o "programa de integridade", onde ficou evidente que a empesa que quer celebrar um contrato com a administração pública é imprescindível apresentar e comprovar o programa de compliance.

O Chief Compliance Officer (CCO) é uma figura que nasce nesse cenário para cuidar das peculiaridades de casos com condutas errôneas. É um profissional responsável pela gerência do compliance da empresa. Ou seja, um executivo com o encargo de avalizar que os atos praticados pelos funcionários estão em conformidade com as regras internas e com os regulamentos exteriores à companhia. Em geral, o $C C O$ acaba sendo algum funcionário do jurídico dessa empresa, pelo fato de ser conhecedor de leis. 
Existe a necessidade dele se relacionar com todos da empresa e transitar em todas as áreas da mesma, pois se o próprio não tiver esse bom relacionamento, ele não alcançará os seus objetivos. Tem como função analisar as mensagens e trocar informações com todos os funcionários da organização, seja de qualquer área e em qualquer hierarquia dentro dela, tendo como foco principal o sujeito que cometeu a irregularidade. O CCO é solucionador de problemas e não deve acumular funções (erro muito grave cometido nas empresas).

Há a necessidade de ser alguém que domina o negócio daquela organização, além de ter um conhecimento na área de finanças e regulações. Tem que ser um servidor íntegro, com independência e autonomia para atuar e transitar por todas as áreas da empresa e que tenha facilidade ao se comunicar com os demais funcionários.

Em conformidade com o acima dito, Helena Costa e Marina Araújo (2013, p.223) mencionam:

\begin{abstract}
A estrutura que responderá pelo setor de compliance empresarial, seja ela centrada em uma pessoa, em uma junta de pessoas, ou ainda em um representante externo, não definirá as decisões a serem tomadas por esta companhia. Ela é apenas o alerta sobre os riscos evidentes e inerentes das decisões. A afirmação até pode parecer um anto óbvia, mas muitas vezes parte-se do pressuposto que o compliance officer pode e deve fazer o impossível para evitar qualquer tipo de conduta ilícita ou indesejada na companhia. Se assim o fosse, o compliance officer deveria ser, em verdade, o executivo principal da companhia e não apenas uma área de assessoria na administração.
\end{abstract}

O $C C O$ se assemelha muito com a função de um criminólogo, pois tem que dominar tudo o que acontece na companhia, mas não cabe somente a ele todas as responsabilidades da mesma, e sim, as responsabilidades que se relacionam com as condutas dos funcionários da empresa.

O Decreto 8.420/15 apresenta em seu artigo 42 e diversos incisos, parâmetros de existência e aplicação para o programa de integridade que as empresas devem ter para um eficaz compliance.

Com a implantação da Lei Anticorrupção e o Decreto acima mencionado há a precisão de criação de Códigos de Conduta e de Ética dentro dessas empresas, e ambos são planejados e elaborados de maneira diferentes: a) Código de Ética: missão, visão, valor da empresa; princípios e pilares que sustentam essa empresa; definição dos stakeholders; b) Código de Conduta: descrição do padrão de condutas a serem seguidas; descrição da existência de medidas disciplinares (descrição "pode ou não pode"); divulgação de canais e apoios ao denunciante de má conduta e sigilo. 
TERRON, Leticia Sangaleto; MEDEIROS NETO, Elias Marques. Lei de lavagem de dinheiro e regras do COAF - pontos de cuidado e importância do Compliance

\section{Conclusão}

Ao lado do compliance, o problema da prevenção da lavagem de dinheiro passou a ser foco nas últimas décadas, e ambos caminham juntos no combate à criminalidade nas fases desse crime. A lavagem de dinheiro é a forma abraçada por sujeitos fraudulentos que visam implantar o dinheiro advindo de um crime para dentro da economia legalizada com o intuito de se esconder a origem criminosa desses recursos.

A dependência com atividades legais é a base do sucesso do crime de lavagem de dinheiro perfazendo com que o legislador identifique as atividades mais aptas utilizadas por esses criminosos, buscando maior controle sobre aqueles que praticam essas atividades.

É nesse ambiente de segurança de atividade legal que o compliance aparece, pois os procedimentos e controles a serem levados em consideração são estipulados pelas regras de ética e conduta que uma empresa tem que seguir. Para que se tenha um eficaz combate ao crime de lavagem de dinheiro é necessário que as empresas ajam em concordância com as regulações existentes e o compliance é o elemento mais ativo na demonstração de responsabilidade empresarial na luta a esse crime, pois delineia as características de um programa ideal pelo fato de ser perpetrado na tríade de prevenção, detecção e remediação.

O compliance implanta-se entre as fundamentais intenções da boa governança corporativa, logo, suas tarefas devem abranger com cuidado a reavaliação dos controles internos para a preparação das declarações financeiras, a assimilação e a estimativa dos possíveis riscos, a disposição e conservação de aprimorados meios tecnológicos para identificação de transações irregulares, e se assim detectadas, sejam imediatamente levados a conhecimento as autoridades adequadas, como o Conselho de Controle de Atividades Financeiras (COAF).

Para se inserir o programa de compliance, é necessário, primeiramente, a adesão do alto escalão da empresa, pois somente assim haverá integridade do programa. Sem o empenho integral e eficaz da direção da companhia, não há engajamento dos demais servidores da mesma. Essas regras devem abarcar todo e qualquer empregado e precisam demonstrar a propagação da cultura do programa de compliance adquirido pela empresa, compreendendo além de canais de diálogo (não só para explicação de dúvidas), mas, inclusive como meio de comunicação de denúncias. Além do mencionado, um acompanhamento permanente é importantíssimo para a continuação e inteireza do compliance, assim como uma equipe independente com poder de decisão.

O programa de compliance nas empresas, por mais que esteja previsto na legislação brasileira, ainda é pouco difundido no país. Há a necessidade urgente de se inventar condutas 
TERRON, Leticia Sangaleto; MEDEIROS NETO, Elias Marques. Lei de lavagem de dinheiro e regras do COAF - pontos de cuidado e importância do Compliance

dentro das corporações com o intuito de prevenir o crime de lavagem de dinheiro. As normas do compliance são cridas a partir do progresso das medidas de prevenção e combate a esse crime.

Há uma preocupação constante na prevenção dos danos causados pelos atos criminosos na lavagem de dinheiro, onde o compliance se torna uma alternativa para a aplicação do bem jurídico metaindividual da ordem econômica.

Conclui-se, assim, que o programa de compliance é o meio mais eficiente para um combate ao crime de lavagem de dinheiro e um modo de prevenção para que a empresa não cometa ilegalidades em eu seio, pois ter um alto grau de compromisso é uma condição primordial para uma governança eficaz em um mundo globalizado.

Admitir determinados deveres que devam ser lidados pelos sujeitos e instituições que atuam no mercado econômico está relacionado aos empenhos efetuados para se prevenir o crime de lavagem de capitais. A adoção das obrigações do compliance pela Lei de Lavagem de Dinheiro, Lei 9.613/98, explicita este juízo, passando o Estado a agir diretamente sobre transações duvidosas ou mesmo sobre aquelas transações que frequentemente servem para o exercício deste delito.

O desenvolvimento das regulações que se arrolam ao combate e prevenção à lavagem de dinheiro (que contêm os normativos da COAF e de órgãos reguladores) evidencia o desígnio de alcançar as esferas com menor grau de regulação ou fiscalização.

O programa de compliance e o combate ao crime de lavagem de dinheiro estão correlacionados e é um "caminho sem volta", quando relacionado ao aumento da compreensão de setores, organizações, pessoas físicas ou operações comprometidas pela colaboração privada no combate e prevenção à lavagem de dinheiro. Dessa maneira, é conciso edificar uma tradição empresarial ética sólida e que seja concentrada pelos cooperadores para que ajam de forma correta e enérgica diante dos conflitos existentes no dia-a-dia.

\section{Referências}

ABIN. Lavagem de Dinheiro. Disponível em: http://www.abin.gov.br/atuacao/areasprioritarias/lavagem-de-dinheiro/. Acesso em: 26 maio 2019.

ANTONIK, Luis Roberto. Compliance, ética, responsabilidade social e empresarial: uma visão prática. Rio de Janeiro: Alta Books, 2016. 
ARAS, Vladimir. A investigação criminal na nova lei de lavagem de dinheiro. Instituto Brasileiro de Ciências Criminais. Boletim - 237 - agosto /2012. Disponível em: https://arquivo.ibccrim.org.br/boletim_artigo/4671-A-investigacao-criminal-na-nova-lei-delavagem-de-dinheiro. Aceso em: 10 jun. 2020.

ARO, Rogério. Lavagem de dinheiro - origem histórica, conceito, nova legislação e fases. Revista Jurídica da Universidade do Sul de Santa Catarina, 2013. Disponível em: http://www.portaldeperiodicos.unisul.br/index.php/U_Fato_Direito/article/viewFile/1467/112 3. Acesso em: 20 maio 2019.

ARROYO ZAPATERO, Luis; NIETO MARTÍN, Adán (org). El Derecho Penal Económico en la era compliance. Valencia: Tirant lo Blanch, 2013.

BADARÓ, Gustavo Henrique; BOTTINI, Pierpaolo Cruz. Lavagem de dinheiro: aspectos penais e processuais penais. 2. ed. São Paulo: Revista dos Tribunais, 2013.

BARROS, Marco Antônio de. Lavagem de dinheiro: implicações penais, processuais e administrativas: Análise sistemática da Lei 9.613, de 3 de março de 1998. São Paulo: Oliveira Mendes, 1998.

BARROS, Marco Antônio de. Lavagem de capitais e obrigações civis correlatas: com comentários, artigo por artigo, à Lei 9.613/1998. 4. ed. São Paulo: Editora Revista dos Tribunais, 2013.

BRASIL. COAF - Conselho de Controle de Atividades Financeiras. Relatório de Atividades, 2016.

BITTENCOURT, Sidney. Comentários à Lei Anticorrupção: Lei 12.846/ 2013. Revista de Doutrina da $4^{\mathrm{a}}$ Região publicação da escola da magistratura do TRF da $4^{\mathrm{a}}$ Região EMAGIS, ago. 2015.

BOTELHO, Alexandre. COAF, o que você sabe sobre ele? IPLD, 2018. Disponível em: https://www.ipld.com.br/coaf-o-que-voce-sabe-sobre-ele/serie-coaf-01-propor-e-coordenarmecanismos-de-cooperacao-e-de-troca-de-informacoes-de-inteligencia-financeira. Acesso em: 26 maio 2019.

BRAVO, Ricardo; AFONSO, José Roberto. Terrorismo: Financiamento, Detecção, Integração de Dados e Privacidade. DPU - EDIÇÃO ESPECIAL - 2019 - Seção 2 Constitucionalismo, Direitos Fundamentais e Reformas. Disponível em: https://www.researchgate.net/profile/Jose_Roberto_Afonso/publication/338176210_Terroris mo_Financiamento_Deteccao_Integracao_de_Dados_e_Privacidade/links/5e04e53d92851c83 649c9a96/Terrorismo-Financiamento-Deteccao-Integracao-de-Dados-e-Privacidade.pdf. Acesso em: 16 fev. 2020.

CALLEGARI, André Luís. Imputação objetiva: lavagem de dinheiro e outros temas de Direito Penal. Porto Alegre: Livraria do Advogado, 2001.

CALLEGARI, André Luis; WEBER, Ariel Barazzetti. Lavagem de dinheiro. São Paulo: Atlas, 2014. 
CLAYTON, Mona. Entendendo os desafios de Compliance no Brasil: um olhar estrangeiro sobre a evolução do Compliance anticorrupção em um país emergente. In: DEBBIO, Alessandra Del; MAEDA, Bruno Carneiro; AYRES, Carlos Henrique da Silva (coord.). Temas de anticorrupção e Compliance. Rio de Janeiro: Elsevier, 2013.

COIMBRA, Marcelo Aguiar; MANZI, Vanessa Alessi. Manual de compliance: preservando a boa governança e a integridade das organizações. São Paulo: Atlas, 2010.

COMPLOIER, Mylene. O papel da atividade de Inteligência Financeira na prevenção e repressão aos crimes praticados por organizações criminosas . Tese (Doutorado Político e Econômico) - Universidade Presbiteriana Mackenzie, São Paulo, 2019. Orientador: Gianpaolo Poggio Smanio. Disponível em: http://tede.mackenzie.br/jspui/handle/tede/4083\#preview-link0. Acesso em: 14 fev. 2020.

\section{CONSELHO ADMINISTRATIVO DE DEFESA ECONÔMICA. Guia Programas de}

Compliance: instrução sobre estruturação e benefícios da adoção dos programas de compliance concorrencial. CADE, 2016. Disponível em: http://www.cade.gov.br/acesso-ainformacao/publicacoes institucionais/guias_do_Cade/guia-compliance-versao-oficial.pdf. Acesso em: 03 jul. 2019.

COSTA, Helena Regina Lobo da; ARAÚJO, Marina Pinhão Coelho. Criminal compliance na AP 470. RBCCRIM n.106, 2013.

CGU, PROGRAMA DE INTEGRIDADE: Diretrizes para Empresas Privadas. Equipe Técnica: Diretoria de Promoção da Integridade, Acordos e Cooperação Internacional. CGU, 2015. Disponível em: https://www.cgu.gov.br/Publicacoes/etica-eintegridade/arquivos/programa-de-integridade-diretrizes-para-empresas-privadas.pdf. Acesso em: 27 maio 2019.

FIGUEIREDO, Danniel; CHAGAS, Inara. COAF : o que é e como funciona?. Politize, 2019. Disponível em: https://www.politize.com.br/coaf/. Acesso em: 27 maio 2019.

FREITAS JUNIOR, Dorival. A responsabilidade da pessoa jurídica na Lei

Anticorrupção. Tese Pontífica Universidade Católica de são Paula - PUC-SP, 2017. Disponível em:

https://tede2.pucsp.br/bitstream/handle/20243/2/Dorival\%20de\%20Freitas\%20Junior.pdf. Acesso em: 08 jun.2020.

KEMPFER, Marlene. BATISTI, Beatriz Miranda. Estudos sobre o compliance para a prevenção da corrupção nos negócios públicos: ética, ciência da administração e direito.

Revista do Direito Público, Londrina, v. 12, n. 2, p. 273-307, ago. 2017. DOI: http://dx.doi.org/10.5433/1980-511X.2017v12n2p273. Acesso em: 18 fev. 2020.

LIMA, Vinicius de melo; GULARTE, Caroline de Melo. Compliance e prevenção ao crime de lavagem de dinheiro. Revista do Ministério Público do RS, Porto Alegre, n. 82 jan. 2017 - abr. 2017 p. 119-145. Disponível em:

https://www.amprs.com.br/public/arquivos/revista_artigo/arquivo_1527273276.pdf. Acesso em: 07 fev. 2020. 
MACHADO, Aíra Rocha; PASCHOAL, Bruno. Monitorar, investigar, responsabilizar e sancionar: a multiplicidade institucional em casos de corrupção. Novos estud. CEBRAP, São Paulo, v .35, n. 1, mar. 2016. Disponível em: https://doi.org/10.25091/s01013300201600010001. Acesso em: 18 fev. 2020.

MACHADO, Leonardo Marcondes . O novo crime de "lavagem de dinheiro" e a infração penal antecedente: legislação de terceira geração. JusBrasil, 2012. Disponível em:

https://leonardomachado2.jusbrasil.com.br/artigos/121940761/o-novo-crime-de-lavagem-dedinheiro-e-a-infracao-penal-antecedente-legislacao-de-terceira-geracao. Acesso em: 23 maio 2019.

MASCHIETO, Marcos José. Comentários à Lei 9613, de 1 de março de 1998 (Crimes de "LAVAGEM" ou ocultação de bens, direitos e valores). Prisma Jurídico, v. 1, 2002.

Disponível em: https://periodicos.uninove.br/prisma/article/view/512. Acesso em: 07 jun. 2020.

MENDRONI, Marcelo Batlouni. Crime de lavagem de dinheiro. 4. ed. São Paulo: Atlas S.A, 2018.

SAAD, Ricardo Andrade; MACHADO, Diogo de Oliveira. Os valores da corrupção: administração de bens apreendidos e confiscados. Revista Direito GV, São Paulo, v. 13, n. 2, 484-519, maio/ago. 2017. ISSN 2317-6172. Disponível em:

http://www.scielo.br/pdf/rdgv/v13n2/1808-2432-rdgv-13-02-0484.pdf. Acesso em: 08 fev. 2020.

SANTANA, Paulo Ricardo. Compliance como ferramenta do Direito Eleitoral e a importância da due diligence nas contas da campanha. Revista SLC, Solução em Licitação e Contratos, Ano 2, n. 17, agosto de 2019.

SEVERINO. Antonio Joaquim. Metodologia do trabalho científico. São Paulo: Cortez, 2017.

SILVEIRA, Renato de Mello Jorge; SAAD-DINIZ, Eduardo. Compliance, direito penal e lei anticorrupção. São Paulo: Saraiva, 2015.

UNODC. Convenção das Nações Unidas contra a Corrupção. UNODC, 2019. Disponível em: https://www.unodc.org/lpo-brazil/pt/corrupcao/convencao.html. Acesso em: 20 maio 2019.

VIEIRA, Vânia Lúcia Ribeiro. A atuação do COAF na prevenção à lavagem de dinheiro à luz da Teoria da Regulação Responsiva. Revista de Direito Setorial e Regulatório, Brasília, v. 4, n. 1, p. 263-288, maio 2018. Disponível em:

http://www.mpsp.mp.br/portal/page/portal/documentacao_e_divulgacao/doc_biblioteca/bibli servicos_produtos/bibli_boletim/bibli_bol_2006/Rev-Dir-Set-Regulat_v.4_n.1.13.pdf. Acesso em: 20 fev. 2020.

I COLETÂNEA DE CASOS BRASILEIROS DE LAVAGEM DE DINHEIRO, EDIÇÃO COMEMORATIVA PELOS 10 ANOS DO CONSELHO DE CONTROLE DAS ATIVIDADES FINANCEIRAS. 2013. Disponível em: www.fazenda.gov.br/centraisde...pdf/.../CasosECasos_1edicao_agosto2013.pdf. Acesso em: 27 de maio 2019. 